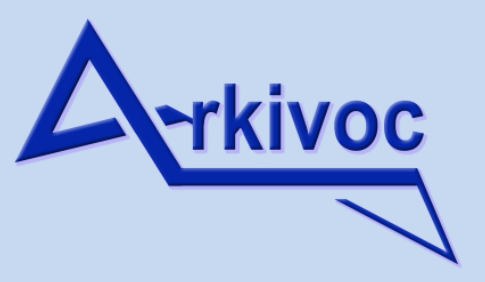

Free to Authors and Readers
A Platinum Open Access Journal for Organic Chemistry

Paper

DOAJ Seal
Arkivoc 2021, part x, 90-105

\title{
Solid phase synthesis of bicyclic pyrrolidines
}

\author{
Paolo Quadrelli \\ University of Pavia, Department of Chemistry, Viale Taramelli 12, 27100 - Pavia (Italy) \\ Email:paolo.quadrelli@unipv.it
}

Celebrating Prof. Ronald E. Grigg, Emeritus Professor of the University of Leeds

Received 09-07-2021

Accepted Manuscript $10-12-2021$

Published on line 11-08-2021

\begin{abstract}
The preparation of bicyclic pyrrolidines, stable and easy to isolate, is performed through both classical solution chemistry and on solid support. A new linker strategy is presented based on the concept of REM resin approach. Starting from a suitably derivatized Wang's resin, the linker can be REgenerated after cleavage of the product and functionalized to start a new synthetic cycle via a Michael reaction. In the present work a vinyl sulfone supported on a Wang's resin is able to undergo a Michael reaction with an amino acid derivative; the obtained adduct serves as a precursor for azomethine ylide generation, which is conveniently trapped with $\mathrm{N}$-methyl-maleimide. The results are presented and discussed in the light of the experimental conditions applied as well as the method chosen for the cleavage of the product and resin regeneration.
\end{abstract}

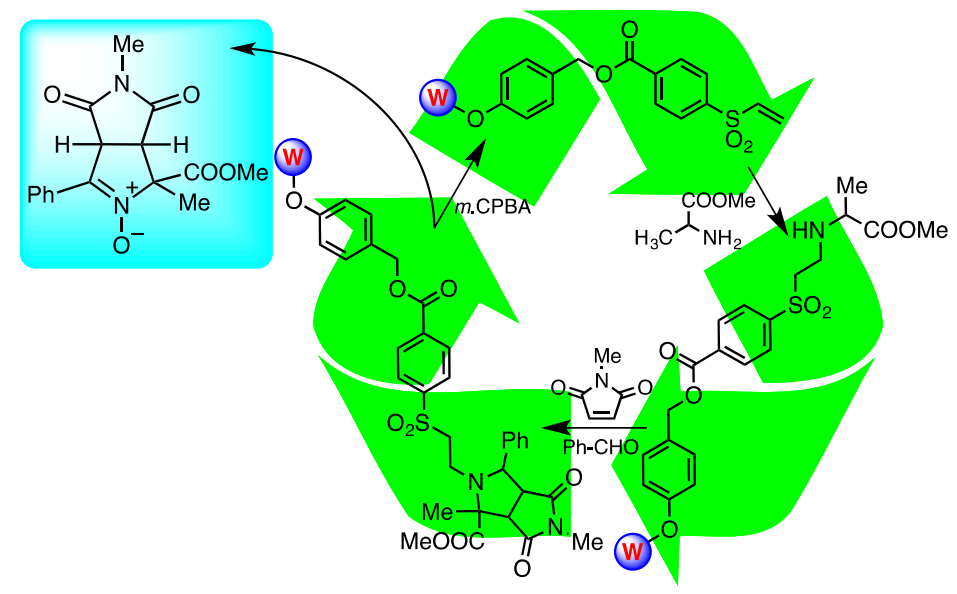

Keywords: Pyrrolidines, solid-phase synthesis, Wang resin, azomethine ylide, 1,3-dipolar cycloaddition 


\section{Introduction}

Cycloaddition reactions are among the most powerful synthetic methods towards complex structures. The development and application of the 1,3-dipolar cycloaddition, an important member of this reaction class, has grown immensely the ability to build various five-membered heterocycles efficiently. Azomethine ylides are commonly used as dipoles for the synthesis of pyrrolidine scaffolds, an important motif in natural, pharmaceutical, and biological compounds. ${ }^{1}$ The reaction between azomethine ylides and cyclic dipolarophiles allows access to polycyclic products with considerable complexity with high yield in a regio- and stereocontrolled manner. The most attractive feature of the 1,3-dipolar cycloaddition of azomethine ylides is the possibility to generate pyrrolidines with multiple stereocenters in a single step. ${ }^{2}$ The interest in asymmetric synthesis is continuously increasing owing to the constant demand for enantiomerically enriched molecules. The main challenge in this area is to create the maximum number of stereogenic centers in one reaction step by employing the minimum number of reagents, often with the help of catalysts. ${ }^{3}$ Azomethine ylides have four $\pi$ electrons spread over the three-atom C-N-C unit; as such, they must be represented by a zwitterionic (or diradical) form. The most common representation has a positive charge located on the nitrogen atom and a negative charge distributed over the two carbon atoms. The extent of negative charge on each carbon atom is determined by the nature and number of substituents at these carbons. Alternatively, two resonance forms with the positive and negative charges on the carbon atoms can be drawn to represent the 1,3-dipole (Figure 1). ${ }^{4}$ The nature of these 1,3-dipoles and their generation protocols nicely fit with the applications in Solid Phase Organic Synthesis (SPOS) as well as combinatorial approaches to medicinally active compounds. ${ }^{5}$

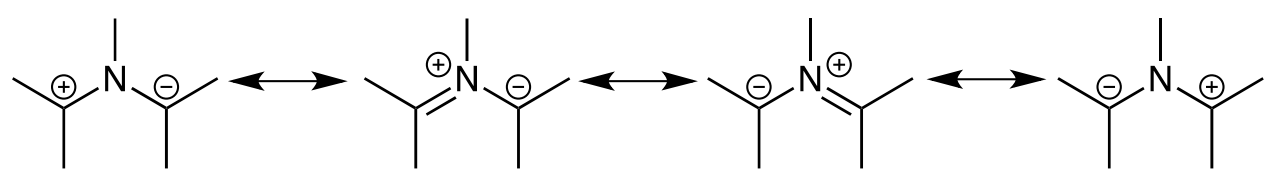

Figure 1. Resonance forms of azomethine ylides.

Several examples have been reported in the literature concerning different approaches to pyrrolidines and bicyclic derivatives with the help of solid phase methodologies. Preparation of highly substituted pyrrolidines (proline analogs) was achieved using a three component 1,3-dipolar cycloaddition of a resin bound azomethine ylide (Scheme 1a). The synthesis utilizes a series of hydroxybenzaldehydes attached to Wang's resin $\mathbf{1}$ via a Mitsunobu coupling followed by reaction with a variety of $\alpha$-amino esters $\mathbf{2}$ and $N$-phenylmaleimide. The reaction afforded resin-bound compounds $\mathbf{3}$ as a single component. ${ }^{6}$ Alternatively, Wang's resin-bound dipolarophiles can be reacted with an in situ generated azomethine ylide formed from methyl 2(benzylideneamino)acetate, $\mathrm{LiBr}$ and DBU. ${ }^{7}$

Substituted pyrrolidines were prepared by 1,3-dipolar cycloaddition of an in situ generated azomethine ylide with a trityl-resin-supported maleimide 4 (Scheme $1 \mathrm{~b}$ ) in the presence of methyl 2-amino-2phenylacetate $\mathbf{5}$ and benzaldehyde, at reflux with toluene and acetic acid. Cleavage of the product from the resin 6 with TFA afforded the desired pyrrolidines in 39\% overall yield and $>95 \%$ purity. ${ }^{8}$

The direct precursor of azomethine ylides, an $\alpha$-silylimine, was linked to a Merrifield resin $\mathbf{7}$ (Scheme 1c); by thermal 1,2-silatropy onto the imino nitrogen or by treatment with a trifluorosilane as a quaternization and desilylation reagent, the resulting 1,3-dipole was then reacted with $N$-phenyl-maleimide to give the resinlinked five membered heterocycles which on cleavage from the resin afforded a range of pyrrolidine 
derivatives. $^{9}$ A similar 1,2-silatropic shift was applied at resin-bound $\alpha$-silylimine in a traceless synthesis of pyrrolidines. ${ }^{10}$ Other variants on the general illustrated protocol based on Wang's ${ }^{11}$ or common hydroxymethyl-polystyrene resins ${ }^{12}$ are proposed in the literature offering a wide scenario of entries to simple pyrrolidines or bicyclic derivatives.

(a) Wang's resin synthesis of bicyclic pyrrolidines; $\underline{\text { Ref. } 6}$

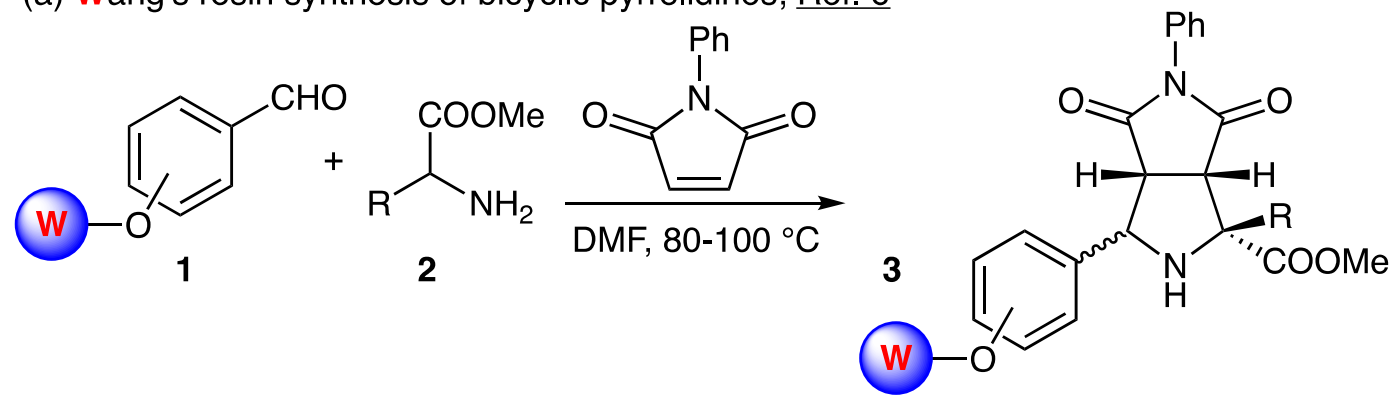

(b) Trityl resin synthesis of bicyclic pyrrolidines; Ref. 8

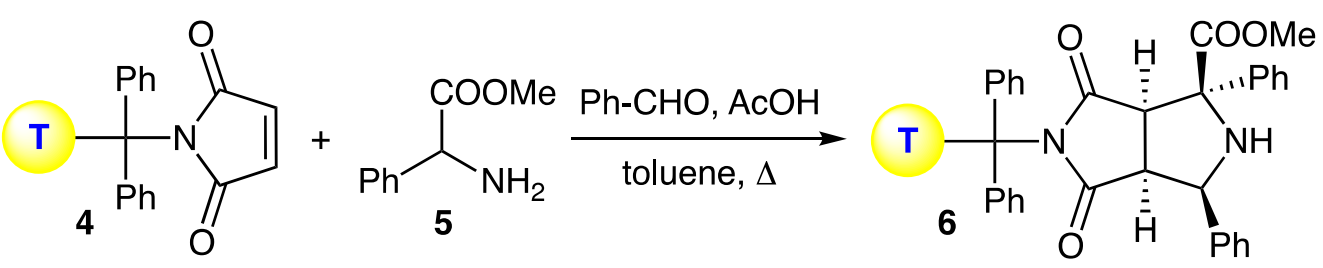

(c) Merrifield resin synthesis of bicyclic pyrrolidines; Ref. 9
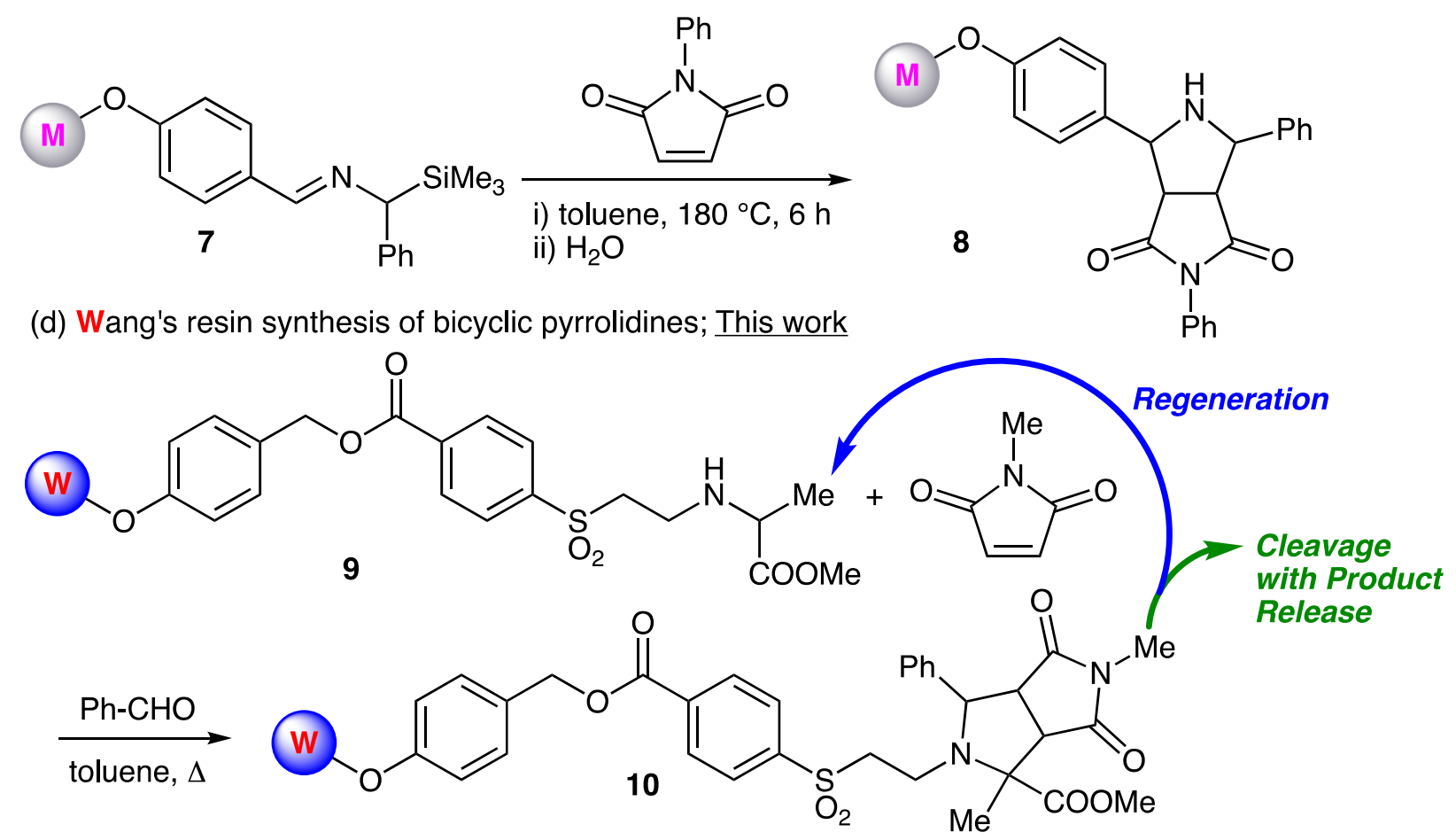

Scheme 1. Synthetic approaches to bicyclic pyrrolidines through SPOS.

A valid alternative to the proposed approaches to bicyclic pyrrolidines is represented by the solid phase cycloadditions of azomethine ylides generated on resins via 1,2-prototropy ${ }^{13}$ and trapped with suitable dipolarophiles. Specifically, a new linker strategy to bicyclic pyrrolidines is presented in the present work (Scheme $1 \mathrm{~d}$ ) based on the concept of REM resin approach. ${ }^{14}$ Starting from a suitably derivatized Wang's resin, 
the linker can be REgenerated after cleavage of the product and functionalized to start a new synthetic cycle via a Michael reaction. In the present work we will support a vinyl sulfone on a Wang's resin able to undergo a Michael reaction with amino acid derivatives; the obtained adducts will serve for the azomethine ylide generation, conveniently trapped with $\mathrm{N}$-methyl-maleimide. The results are presented and discussed in the light of the experimental conditions applied as well as the method chosen for the cleavage of the product and resin regeneration. To verify the synthetic pathway on solid phase, a solution chemistry study on model substrates was conducted in parallel, with complete characterization of the structures both in solution and on solid phase by means of spectroscopic investigations.

\section{Results and Discussion}

Part A - Solution chemistry. The preparation of the ethyl 4-vinylsulfonylbenzoate (18) is reported in literature $^{15}$ and the general approach is shown in Scheme 2. By adapting the literature procedures, the synthetic pathway started from the commercially available 4-aminobenzoic acid (11) needed for the preparation of the 4-mercaptobenzoic acid (13); the well-documented procedure requires diazotization with in situ generated $\mathrm{HNO}_{2}$ and treatment with carbonodithionic acid $O$-ethyl ester potassium salt to afford the disulfide 12 and reduction with zinc in acetic acid solution. Alternatively, $\mathrm{Na}_{2} \mathrm{~S} / \mathrm{S}$ can be used in the first synthetic step to convert 11 into 12. The overall yields are around 40\% after two steps. ${ }^{16,17}$ Derivatization with 2-bromoethanol in the presence of two equivalents of $\mathrm{NaHCO}_{3}$ allowed us to obtain the sulfide 14 in $95 \%$ yield.

The same reaction with 2-chloroethanol is slower and requires five days at $\mathrm{rt}$ to produce compound 14 in just $38 \%$ yield. The dry compound 14 was then reacted with $\mathrm{SOCl}_{2}$ to obtain chloride 15, which was not isolated but immediately converted into the ester 16 in quantitative yield. Oxidation with $\mathrm{H}_{2} \mathrm{O}_{2} / \mathrm{AcOH}$ furnished the ethyl 4-(2-chloroethylsulfonyl)-benzoate (17) in 76\% yield. Finally, base-promoted elimination with triethylamine afforded the desired vinyl-derivative 18 in $87 \%$ yield. All the compounds isolated were checked spectroscopically to verify the correct advancement of the synthetic steps; in particular, compound $16{ }^{1} \mathrm{H}$ NMR spectrum showed the presence of the two methylenes of the sulfide chain as triplets at $\delta 3.30$ and $3.65 \mathrm{ppm}$; the chemical shifts slightly increase in the sulfonyl derivative 17 ( $\delta 3.55$ and 3.76 ppm) while the presence of the $-\mathrm{CH}=\mathrm{CH}_{2}$ double bond in $\mathbf{1 8}$ is demonstrated by the signals in the expected region at $\delta 6.10$ and $6.70 \mathrm{ppm}$. All the spectroscopic data are in nice keeping with those reported in literature. ${ }^{15-17}$

The vinyl-sulfonyl ester 18 was then used in a Michael reaction with (D,L)-alanine methyl ester 19 conducted in DMF as the solvent at room temperature to obtain the adduct $\mathbf{2 0}$ in $\mathbf{7 8 \%}$ yield. The structure was confirmed through the analytical and spectroscopic data, in particular, in the ${ }^{1} \mathrm{H} \mathrm{NMR} \mathrm{spectrum}\left(\mathrm{CDCl}_{3}\right)$ the presence of a singlet was found at $\delta 3.70 \mathrm{ppm}$, corresponding to the methoxy group of the alanine methyl ester moiety as well as the doublet at $\delta 1.26 \mathrm{ppm}$ relative to the $\mathrm{CH}_{3}-\mathrm{CH}$ - of the amino acid fragment. 


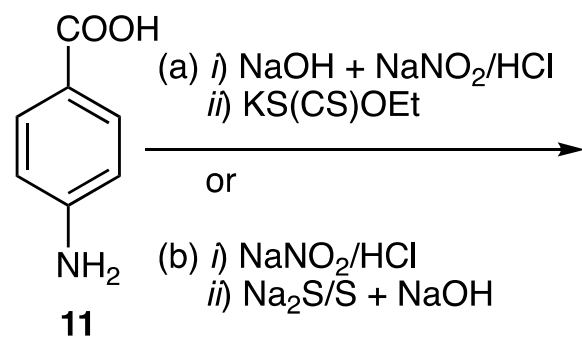<smiles>O=C(O)c1ccc(SSc2ccc(C(=O)O)cc2)cc1</smiles>

12<smiles>CC(=O)OC(C)=O</smiles>

13<smiles>CCOC(=O)c1ccc(S(=O)(=O)CCCl)cc1</smiles>

17<smiles>CCOC(=O)c1ccc(SCCCl)cc1</smiles>

16
$\stackrel{\mathrm{EtOH}}{\longleftarrow}$<smiles>O=C(Cl)c1ccc(SCCCl)cc1</smiles>

15 $\mid \begin{aligned} & \mathrm{X} \smile \mathrm{OH} \\ & \mathrm{XaHCl}, \mathrm{Br} \\ & \text { r.t., } 4 \mathrm{~d}\end{aligned}$

$\mathrm{Et}_{3} \mathrm{~N}$ Benzene<smiles>C=CS(=O)(=O)c1ccc(C(=O)OCC)cc1</smiles>

18<smiles>CC(=O)C(C)N</smiles>

(D,L)-19<smiles>CCOC(=O)c1ccc(S(=O)(=O)CCNC(C)C(C)=O)cc1</smiles>

20

Scheme 2. Synthesis of 4-mercaptobenzoic acid (13), conversion into the 4-vinylsulfonylbenzoic acid (18) and reaction with $(D, L)$-alanine methyl ester (19).

The azomethine ylide 1,3-dipolar cycloaddition reaction was conducted by heating a 1:1:1 mixture of 20, benzaldehyde and $N$-methyl maleimide in refluxing toluene or xylene for four days affording the desired endo cycloadducts $\mathbf{2 1 a , b}$ as mixture $\sim 2: 1$ of diastereoisomers in good yields (Scheme 3 ). 


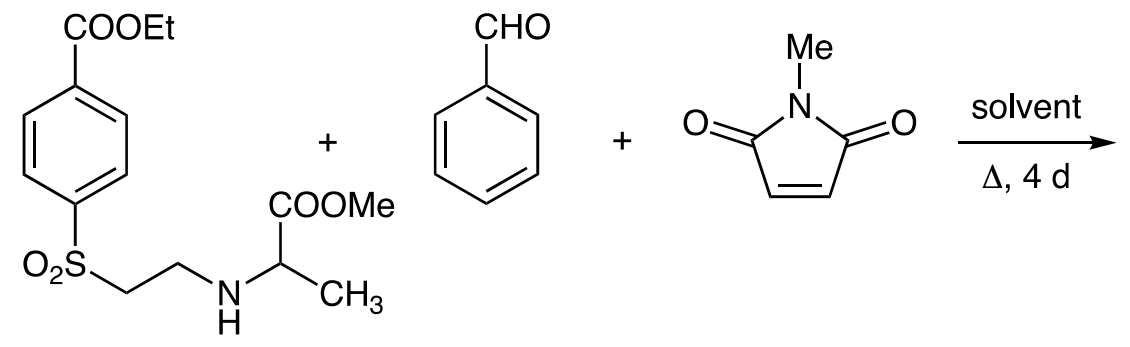

20

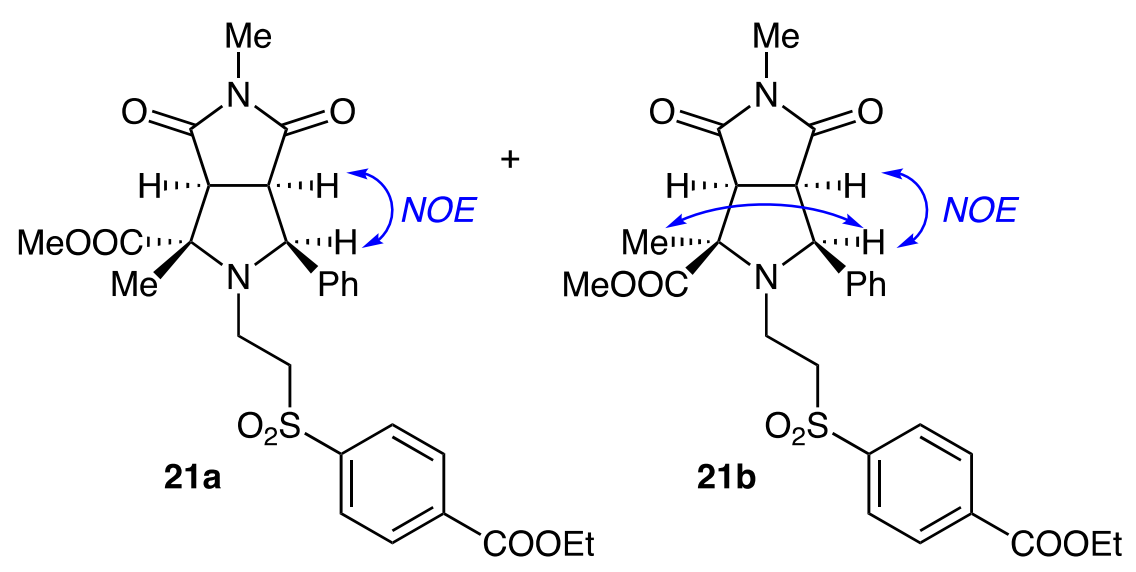

Scheme 3. Synthesis of the methyl 2-(2-((4-(ethoxycarbonyl)phenyl)sulfonyl)ethyl)-1,5-dimethyl-4,6-dioxo-3phenyloctahydropyrrolo[3,4-c]pyrrole-1-carboxylates 21a,b through in situ generated azomethine ylide 1,3dipolar cycloaddition to $\mathrm{N}$-methyl maleimide. Arrows in blue indicate the NOE correlations for stereochemistry determination.

The diastereoisomeric products were separated by column chromatography and fully characterized; the reaction in toluene afforded compound $\mathbf{2 1 a}$ in $43 \%$ yield along with $\mathbf{2 1 b}$ in $18 \%$ yields; negligible differences in terms of chemical yields were observed when the reaction was conducted in xylene as the solvent (21a : 21b, $41 \%$ : $20 \%$ yield).

The structures of the two diastereoisomeric products $\mathbf{2 1 a , b}$ were attributed on the basis of their analytical and spectroscopic data. Noteworthy, in the ${ }^{1} \mathrm{H}$ NMR spectrum of compound 21a, the signal of the benzylic proton in the position (3) is found at $\delta 4.33 \mathrm{ppm}$ coupled with the adjacent proton in (3a) at the junction of the two pentatomic rings found at $\delta 3.44 \mathrm{ppm}$. That these two protons are located on the same side, as shown in Scheme 3, is a result of NOE experiments conducted for determining the stereochemistry of the molecule. Concerning compound 21b, the signal of the benzylic proton in (3) is found at $\delta 4.09 \mathrm{ppm}$ coupled with the adjacent proton in (3a) at the junction of the two pentatomic rings found at $\delta 3.48 \mathrm{ppm}$. NOE experiments confirmed the relative position of these two protons with a new spatial correlation between the benzylic proton and the methyl group at the signal of the benzylic proton is found at $\delta 4.09$ ppm coupled with the adjacent proton at the junction of the two pentatomic rings found at $\delta 1.44 \mathrm{ppm}$ adjacent to -COOMe, defining in this way the stereochemistry of both the stereoisomers. These findings clearly indicate that the reaction proceeds according to the reported imine-azomethine ylide cycloaddition mechanism via an endo Transition State (TS). ${ }^{18,19}$ To corroborate the stereochemical assignments an X-ray analysis allowed to definitively attribute the structure to compound $\mathbf{2 1 b}$ and the ORTEP view is shown in Figure 2. 


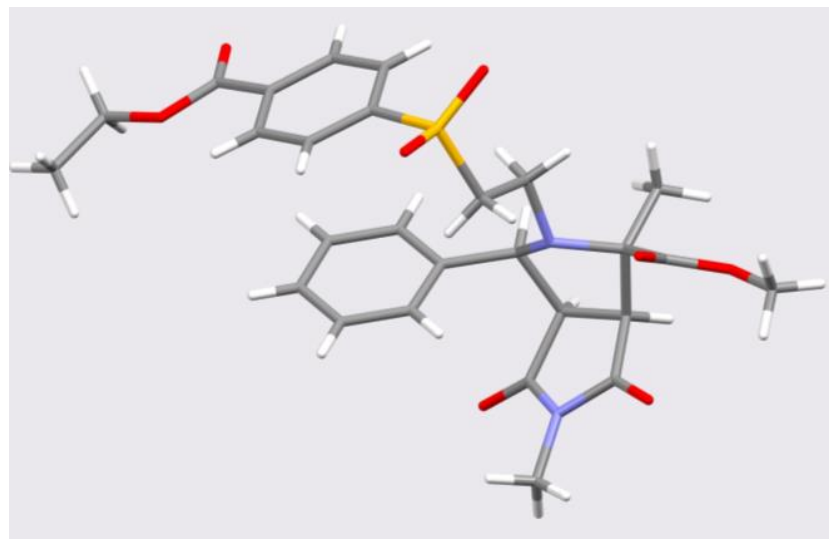

Figure 2. ORTEP representation of compound $\mathbf{2 1 \mathbf { b } .}$

In order to apply the above described synthetic pathway to the SP version, a cleavage test was performed on the major stereoisomer 21a through its oxidation with $m C P B A$ in chloroform solution at $0{ }^{\circ} \mathrm{C}$ for two days. The oxidation triggers the cleavage affording the nitrone 22, vinyl-sulfone 18 being the leaving group (Scheme 4).

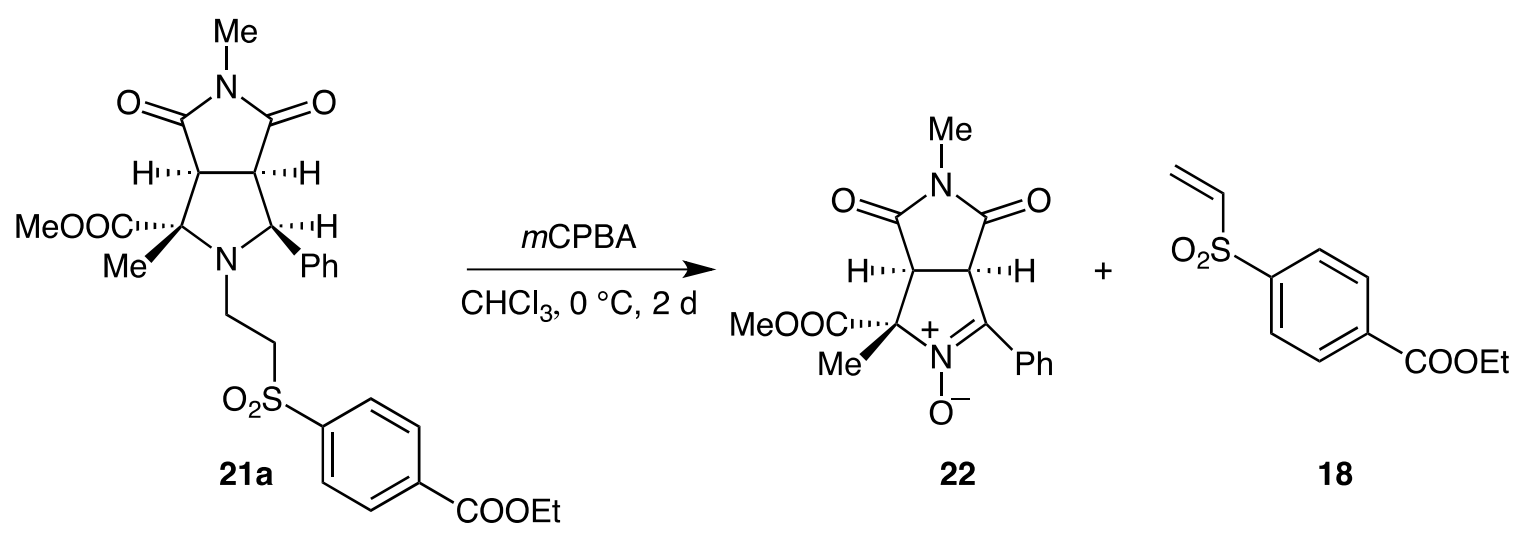

Scheme 4. Cleavage through oxidation and regeneration of the vinyl-sulfonyl benzoic ester.

The nitrone $\mathbf{2 2}$ was obtained in $\mathbf{8 3 \%}$ yield and the vinyl-sulfonyl ester $\mathbf{1 8}$ in $\mathbf{7 5 \%}$ yield; the structure of nitrone $\mathbf{2 2}$ was consistent with the corresponding analytical and spectroscopic data and the method nicely fits the requirements for a $\mathbf{R E M}$ resin synthetic protocol.

Part B - Solid Phase chemistry. The synthesis of the 4-vinylsulfonylbenzoic acid (24) retraces four steps of the previously reported synthesis ${ }^{15-17}$ of the corresponding ethyl ester up to the non-isolated chloride $\mathbf{1 5}$ that is directly oxidized with $\mathrm{H}_{2} \mathrm{O}_{2}$ to give the sulfonyl-benzoic acid 23 in 55\% yield (Scheme 5). Sulfur oxidation slightly shifts the ${ }^{1} \mathrm{H}$ NMR signals of the dimethylene moiety at $\delta 3.85$ and $3.95 \mathrm{ppm}$ with respect to the values corresponding to the alcohol 14. 


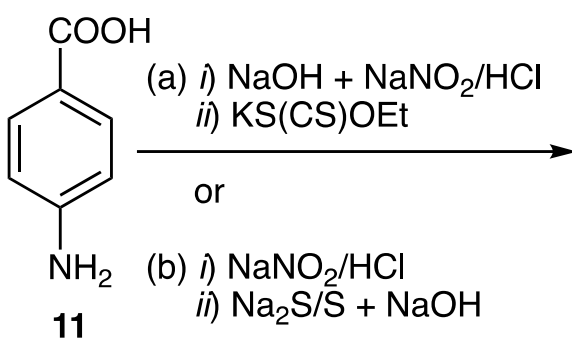

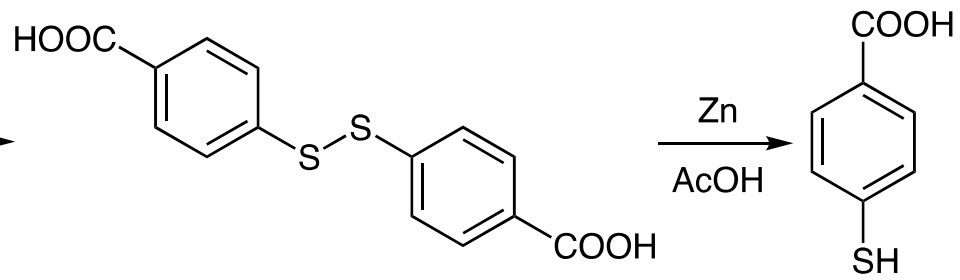

12
13

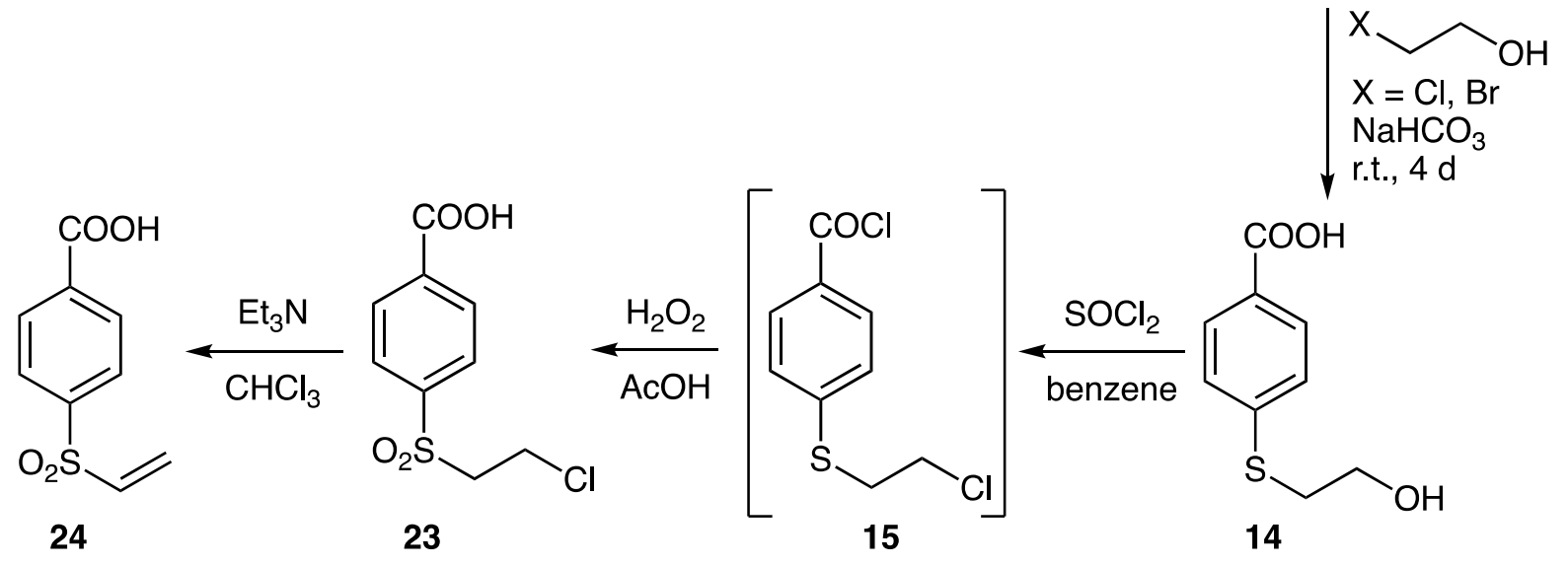

Scheme 5. Synthesis of the 4-vinylsulfonylbenzoic acid (24).

The chloride $\mathbf{2 3}$ is then converted into the vinyl derivative $\mathbf{2 4}$ by simple treatment with triethylamine in chloroform solution, leading to the desired product in $82 \%$ yield. The presence of the vinyl group was verified by the ${ }^{1} \mathrm{H}$ NMR spectrum; signals at $\delta 7.19$ and $6.36 \mathrm{ppm}$ clearly indicate the presence of a $-\mathrm{CH}=\mathrm{CH}_{2}$ double bond. The 4-vinylsulfonylbenzoic acid (24) was then used to prepare the linker for the SPOS approach to azomethine ylide cycloadditions.

Wang's resin ( $p$-benzyloxybenzyl alcohol resin, loading $0.7 \mathrm{mmol} / \mathrm{g}$ ) W-OH, swollen in dry DCM, was coupled with 2.2 equivalents of 4-vinylsulfonylbenzoic acid (24) according to the standard DCC/DMAP coupling procedure (Scheme 6). ${ }^{20-22}$ The esterification on the resin was achieved after $24 \mathrm{~h}$ at $\mathrm{rt}$ under gentle stirring of the suspension and the linker characterization was conducted by gel-phase ${ }^{13} \mathrm{C} \mathrm{NMR},{ }^{20} \mathrm{FT}-\mathrm{IR}$ (Diffuse Reflectance, DR) and microanalyses. Juxtaposition of the ${ }^{13} \mathrm{C} \mathrm{NMR}$ spectra of the pure $\mathbf{W}-\mathbf{O H}$ and the resin $\mathbf{2 5}$ showed that the signals corresponding to the benzylic protons in $\mathbf{W}-\mathrm{OH}$ are found at $\delta 65.7 \mathrm{ppm}$ and are slightly shifted upfield at $65.6 \mathrm{ppm}$ in $\mathbf{2 5}$. In the FT-IR spectra, the $\mathbf{W}-\mathrm{OH}$ OH band at $3430 \mathrm{~cm}^{-1}$ disappeared and the new $\mathrm{C}=\mathrm{O}$ band was found at $1723 \mathrm{~cm}^{-1}$ corresponding to the ester moiety. Finally, incorporation of sulfur in the resin was revealed by elemental analysis; for a $0.7 \mathrm{mmol} / \mathrm{g}$ loading resin, $\mathrm{S}$ requires $2.24 \%$; found $2.30 \%$. The resin 25 was then submitted to the Michael reaction with the $(D, L)$-alanine methyl ester (19) in DMF at $\mathrm{rt}$ for two days. The analysis of the derivative 9 by FT-IR revealed the presence of the NH band at 3324 $\mathrm{cm}^{-1}$; the presence of nitrogen was confirmed through microanalysis: $\mathrm{N}, 0.90 \%$ (required $0.98 \%$ ). In the gelphase ${ }^{13} \mathrm{C}$ NMR spectrum new signals were found corresponding to the alanine moiety included in the structure (see experimental).

The cycloaddition reaction on solid phase was performed by swelling the Michael adduct 9 in dry toluene and adding two equivalents of benzaldehyde and $\mathrm{N}$-methyl maleimide and boiling the suspension with gentle stirring for four days. Higher boiling point solvents (e.g. xylene) could not be used because of resin decomposition. 
<smiles>C=COc1ccc(C(=O)OCc2ccc(Oc3ccc(C(C)=O)cc3)cc2)cc1</smiles>

Wang's resin

24

25<smiles>CC(=O)NCCCSc1ccc(C(=O)OCc2ccc(Oc3ccc(C(C)(F)F)cc3)cc2)cc1</smiles><smiles>COC(=O)C1(C)C2C(=O)N(C)C(=O)C2C(c2ccccc2)N1CCSc1ccc(C(=O)OCc2ccc(Oc3ccccc3)cc2)cc1</smiles>

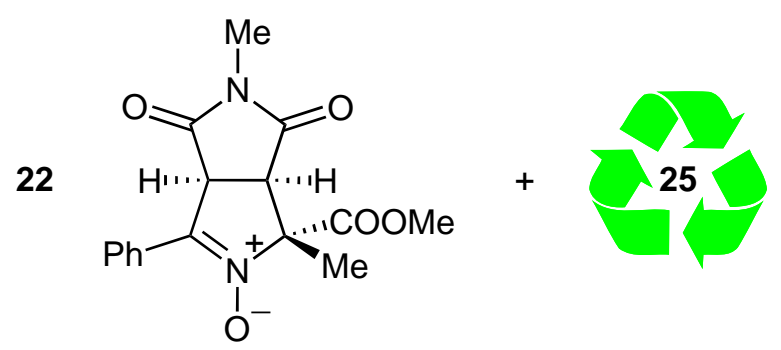

Scheme 6. SPOS of methyl (1R,3aS,6a $R)-1,5$-dimethyl-2-( $\lambda^{1}$-oxidanyl)-4,6-dioxo-3-phenyl-1,3a,4,5,6,6ahexahydro-2 $\lambda^{4}$-pyrrolo[3,4-c]pyrrole-1-carboxylate (22).

The elemental analysis of compound $\mathbf{1 0}$ (mixture of diastereoisomers) confirmed the increase of the nitrogen content from $0.90 \%$ to $1.1 \%$ (required $1.96 \%$ ) and the FT-IR spectrum showed the carbonyl bands at 1700, 1730 and $1760 \mathrm{~cm}^{-1}$. Diagnostic in the ${ }^{13} \mathrm{C}$ NMR spectrum is the presence of the $\mathrm{N}-\mathrm{CH}_{3}$ signal at $\delta 50.7$ $\mathrm{ppm}$. The subsequent cleavage of the bicyclic pyrrolidine from the resin was secured by oxidation with $m$ CPBA in chloroform; only nitrone $\mathbf{2 2}$ was isolated in pure form in $\mathbf{8 3 \%}$ yield, found identical to the sample previously prepared through the solution chemistry pathway. The other could only be detected in very low amount $(<4 \%)$, in the crude reaction mixture. Simultaneously, the vinyl-sulfone functionality on the resin 25 was restored as verified by ${ }^{13} \mathrm{C}$ NMR spectrum that showed the same signal pattern of the original linker.

To confirm the entire synthetic route on the resin, an alternative cleavage protocol was performed by transesterification. Scheme 7 shows the methodology applied, that consisting of treatment of resin 10 with one equivalent of $\mathrm{NaCN}$ in the presence of a large excess of $\mathrm{Et}_{3} \mathrm{~N}$. The mixture was heated at $64{ }^{\circ} \mathrm{C}$ for a couple 
of days under gentle stirring. Simple filtration and washing left the Wang's resin and the major diastereoisomer methyl ester $\mathbf{2 6}$ obtained in $\mathbf{8 7 \%}$ yield. As before, the minor diastereosomer was detected in the crude reaction mixture. Analytical and spectroscopic data of $\mathbf{2 6}$ confirmed the assigned structure, found identical to the compound 21a except for the ester group.

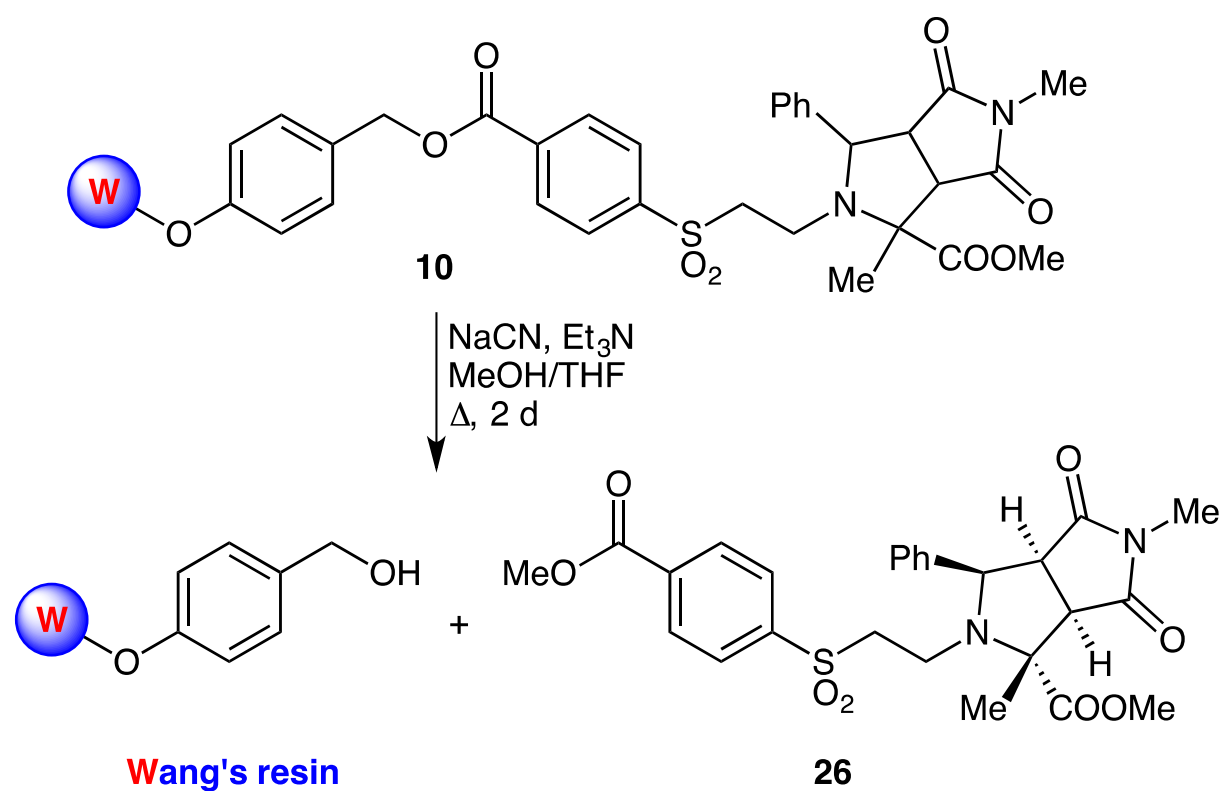

Scheme 7. Cleavage of methyl (1R,3R,3aS,6aR)-2-(2-((4-(methoxycarbonyl)phenyl)sulfonyl)ethyl)-1,5-dimethyl4,6-dioxo-3-phenyloctahydropyrrolo[3,4-c]pyrrole-1-carboxylate from resin 10 through transesterification.

\section{Conclusions}

The SPOS of bicyclic pyrrolidines has been achieved using a new example of REM resin linker (Scheme 8 ). The validation of the methodology was achieved by designing the entire synthetic sequence and performing every single step in classical solution chemistry, subsequently transferred on the solid phase. The synthesis afforded the desired compounds according to robust and reliable protocols; the products were obtained in very good yields and fully characterized, also from the stereochemical point of view.

The use of Wang's resin as solid support to perform the designed syntheses is due the facility of attachment through standard methods of benzoic acid derivatives to the resin core. Moreover, Wang's resin derivatives were easily characterized through simple spectroscopic techniques, available in every research laboratory. No synthetic problems arose when the solution methods were transferred on the solid support. All the reactions were replicated and performed in duplicate, affording the desired products in very good yields. The robustness of the protocol was hence confirmed also on the solid phase and possible variations were verified promptly. For example, the 4-vinyl-sulfinylbenzoic acid was also prepared and linked to the Wang's resin but any attempt to perform the Michael addition of the alanine methyl ester failed, indicating that the presence of a sulfonyl group is mandatory for the key step of the synthesis.

To summarize, the chemistry of 1,3-dipoles is widely employed in organic syntheses, and 1,3-dipoles are indeed very powerful tools to access a variety of heterocycles. Their use in SPOC, if properly designed, 
deserves attention, in spite of the fact that difficulties in translating the solution procedures to SP can be significant. Experimental conditions must be properly regulated on solid phase since some aggressive reagents cannot be used in the presence of a polymeric support or of common solid phase linkers.

The results reported here refer to the preparation of an example of a bicyclic pyrrolidine in the form of nitrone derivative, stable and easy to isolate. An alternative cleavage method was also examined. In both cases, the Wang's resin used as solid support can be recycled. In particular, the oxidation protocol allowed demonstration of the great validity of the REM resin linker use in these synthetic approaches to this type of heterocycle. The resin $\mathbf{2 5}$ is ready to be re-used up to three times without substantial decrease of the chemical yields of the desired products. The synthesis of high-quality, diverse heterocyclic libraries should be the ultimate result of these and other on going investigations.<smiles>CCCCCCCC(=O)c1ccc(C(=O)OCc2ccc(Oc3ccccc3)cc2)cc1</smiles>

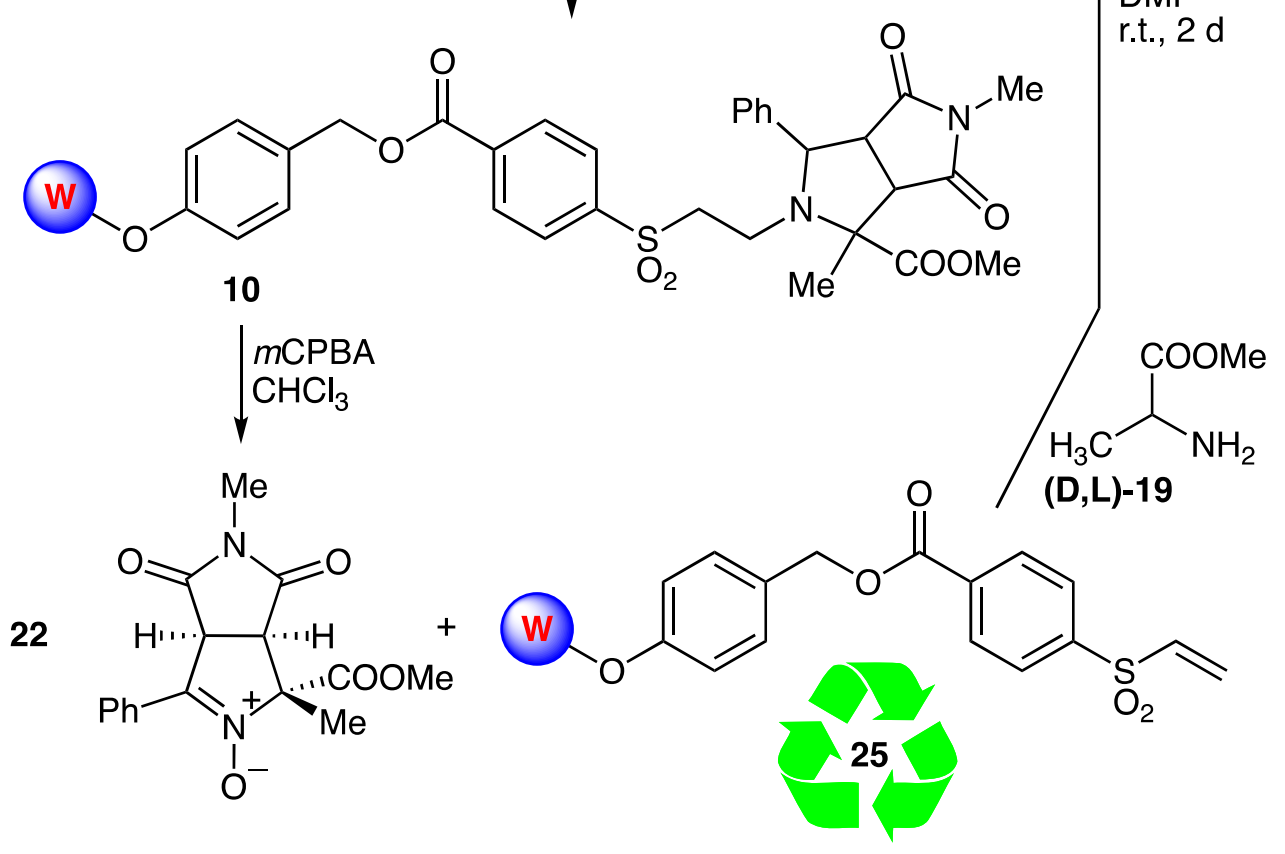

Scheme 8. REM resin linker synthesis of bicyclic pyrrolidines.

This SPOS example was developed at Leeds University with a Marie Curie Fellowship (Grant n. ERBFMBiCT961350) under the guidance of Prof. Ronald Grigg.

The publication of these results once more represents a mark of gratitude I wish to address to a great Professor of Organic Chemistry. 


\section{Experimental Section}

General. All melting points ( $\mathrm{mp}$ ) were determined on a Koffler hot-stage apparatus and are uncorrected. Elemental analyses were done on a elemental analyzer Carlo Erba Mod. 1106. IR spectra (nujol mulls) were recorded on a spectrophotometer Philips PU 9706 and on a Perkin-Elmer FT-IR Paragon 100 in Diffuse Reflectance and absorbtions $(v)$ are in $\mathrm{cm}^{-1} .{ }^{1} \mathrm{H}$ and ${ }^{13} \mathrm{C}$ NMR as well as other NMR spectra were recorded on a Bruker AC 250 and AM 400 spectrometers (solvents specified). Chemical shifts are expressed in ppm from internal tetramethylsilane $(\delta)$ and coupling constants $(\mathrm{J})$ are in Hertz $(\mathrm{Hz})$ : b, broad; s, singlet; bs, broad singlet; $\mathrm{d}$, doublet; t, triplet; q, quartet; m, multiplet. Mass spectra were obtained from VG Autospec (70 eV). Column chromatography and tlc: silica gel $\mathrm{H} 60$ and Whatman PE SIL G/UV washed with $\mathrm{Et}_{2} \mathrm{O} / \mathrm{Et}_{3} \mathrm{~N}$ 9:1 and dried at rt prior to use; eluants: hexane/diethyl ether 9:1 to pure diethyl ether.

Starting and reference materials. Carbonodithionic acid $O$-ethyl ester potassium salt, sodium nitrite, sodium sulfide and alanine methyl ester 19 were purchased from Sigma-Aldrich. Dry DMF was purchased from SigmaAldrich and dry DCM was prepared by refluxing over $\mathrm{LiAlH}_{4}$. Other reagents and solvents were purchased from chemical suppliers and used without any further purification.

All the synthetic steps for the preparation of compounds 12 to 18 are fully reported in literature. ${ }^{15-17}$

Wang's resin ( $p$-benzyloxybenzyl alcohol resin, loading $0.7 \mathrm{mmol} / \mathrm{g}$ ) $\mathbf{W}-\mathbf{O H}$ was purchased from Novabiochem (100-200 mesh).

Synthesis of the ethyl 4-((2-((1-methoxy-1-oxopropan-2-yl)amino)ethyl)sulfonyl)benzoate (20). To a solution of the ester 18 (7.21 g, $30 \mathrm{mmol})$ in dry DMF (50 mL), (D,L)-alanine ethyl ester 19 (4.64 g, $45 \mathrm{mmol})$ dissolved in dry DMF $(50 \mathrm{~mL})$ are added under stirring at rt. After $2 \mathrm{~d}$ the solution is diluted in benzene and evaporated to dryness. The residue was taken up with $\mathrm{Et}_{2} \mathrm{O}$ and washed with $\mathrm{H}_{2} \mathrm{O}$ and the organic layer dried over anhydrous $\mathrm{MgSO}_{4}$. Evaporation of the organic solvent afforded a pale yellow oil corresponding to the product 20. Yield: $8.04 \mathrm{~g}$ (78\%); pale yellow oil. IR $v_{\mathrm{NH}} 3330, v_{\mathrm{C}=0} 1720 \mathrm{~cm}^{-1} .{ }^{1} \mathrm{H} \mathrm{NMR}\left(\mathrm{CDCl}_{3}, 250 \mathrm{MHz}\right): \delta 8.22$ and 7.97 (AA'BB' syst., $2 \mathrm{H}+2 \mathrm{H}$, arom.), $4.42\left(\mathrm{q}, \mathrm{J} 7 \mathrm{~Hz}, 2 \mathrm{H},-\mathrm{OCH}_{2} \mathrm{CH}_{3}\right), 3.70\left(\mathrm{~s}, 3 \mathrm{H},-\mathrm{OCH}_{3}\right), 3.30\left(\mathrm{~m}, 3 \mathrm{H},-\mathrm{CH}-\mathrm{Me}\right.$ and $-\mathrm{CH}_{2}-$ $\left.\mathrm{SO}_{2}-\right), 2.90\left(\mathrm{~m}, 2 \mathrm{H},-\mathrm{CH}_{2}-\mathrm{N}\right), 1.85(\mathrm{~s}, \mathrm{H}, \mathrm{NH}), 1.44\left(\mathrm{t}, 3 \mathrm{H}, \mathrm{J} 7 \mathrm{~Hz},-\mathrm{OCH}_{2} \mathrm{CH}_{3}\right), 1.26\left(\mathrm{~d}, 3 \mathrm{H}, J 6 \mathrm{~Hz},-\mathrm{CH}-\mathrm{CH}_{3}\right) .{ }^{13} \mathrm{C}$ $\mathrm{NMR}\left(\mathrm{CDCl}_{3}, 75 \mathrm{MHz}\right): \delta 175.1$ and $164.7(\mathrm{C}=\mathrm{O}), 142.6,135.0,130.1$ and 127.9 (arom.), $61.6\left(\mathrm{OCH}_{2} \mathrm{CH}_{3}\right), 56.1$ $\left(\mathrm{CH}_{3} \mathrm{O}\right), 56.0\left(\mathrm{CH}_{2} \mathrm{~N}\right), 51.7(\mathrm{CH}-\mathrm{N}), 41.0\left(\mathrm{CH}_{2}-\mathrm{SO}_{2}\right), 18.7\left(\mathrm{CH}_{3} \mathrm{CH}\right), 14.0\left(\mathrm{CH}_{3} \mathrm{CH}_{2} \mathrm{O}\right) . \mathrm{MS}(\mathrm{m} / z): 343(1), 298(3.8)$, 284 (100). Anal. Calcd. for $\mathrm{C}_{15} \mathrm{H}_{21} \mathrm{NO}_{6} \mathrm{~S}$ (343.39): $\mathrm{C}, 52.47 ; \mathrm{H}, 6.16 ; \mathrm{N}, 4.08$. Found: $\mathrm{C}, 52.48 ; \mathrm{H}, 6.20 ; \mathrm{N}, 4.08$.

Synthesis of methyl 2-(2-((4-(ethoxycarbonyl)phenyl)sulfonyl)ethyl)-1,5-dimethyl-4,6-dioxo-3phenyloctahydropyrrolo[3,4-c]pyrrole-1-carboxylates (21a,b). In a round-bottom flask, compound 20 (2.06 g, $6 \mathrm{mmol})$ was dissolved in dry toluene $(30 \mathrm{~mL})$ and benzaldehyde $(0.64 \mathrm{~g}, 6 \mathrm{mmol})$ and $\mathrm{N}$-methyl-maleimide $(0.67 \mathrm{~g}, 6 \mathrm{mmol})$ were added. The solution was boiled for $4 \mathrm{ds}$. The organic solvent of the reaction mixture was then removed at reduced pressure leaving a residue that was submitted to chromatographic separation on silica to get rid of unreacted starting materials. Racemic cycloadducts ( $\mathbf{\pm})-\mathbf{2 1} \mathbf{a}, \mathbf{b}$ were isolated and fully characterized.

Methyl (1S,3S,3aR,6aS)-2-(2-((4-(ethoxycarbonyl)phenyl)sulfonyl)ethyl)-1,5-dimethyl-4,6-dioxo-3-phenyloctahydropyrrolo[3,4-c]pyrrole-1-carboxylate ( \pm )-21a. Yield: $1.40 \mathrm{~g}(43 \%) ;$ white crystals from ethanol, $\mathrm{mp}$ 123-124 ${ }^{\circ} \mathrm{C}$. IR $v_{\mathrm{C}=0} 1690 \mathrm{~cm}^{-1} .{ }^{1} \mathrm{H}$ NMR $\left(\mathrm{CDCl}_{3}, 250 \mathrm{MHz}\right): \delta 8.08$ and 7.61 (AA'BB' syst., $2 \mathrm{H}+2 \mathrm{H}$, arom.), 7.23 and $6.90\left(\mathrm{~m}, 2 \mathrm{H}+3 \mathrm{H}\right.$, arom.), $4.45\left(\mathrm{q}, J 7 \mathrm{~Hz}, 2 \mathrm{H},-\mathrm{OCH}_{2} \mathrm{CH}_{3}\right), 4.33(\mathrm{~d}, J 6 \mathrm{~Hz}, 1 \mathrm{H}, \mathrm{CH}-\mathrm{Ph}), 3.79\left(\mathrm{~s}, 3 \mathrm{H},-\mathrm{OCH}_{3}\right), 3.44$ $(\mathrm{t}, J 6 \mathrm{~Hz}, 1 \mathrm{H},-\mathrm{CH}-\mathrm{CHPh}), 3.32(\mathrm{~d}, J 6 \mathrm{~Hz}, 1 \mathrm{H}, \mathrm{CH}), 3.29$ and $2.55\left(\mathrm{~m}, 2 \mathrm{H}+2 \mathrm{H}, \mathrm{CH}_{2}-\mathrm{CH}_{2}\right), 2.85\left(\mathrm{~s}, 3 \mathrm{H}, \mathrm{CH}_{3}-\mathrm{N}\right), 1.68$ $\left(\mathrm{s}, 3 \mathrm{H}, \mathrm{CH}_{3}\right), 1.45\left(\mathrm{t}, 3 \mathrm{H}, \mathrm{J} 7 \mathrm{~Hz},-\mathrm{OCH}_{2} \mathrm{CH}_{3}\right) .{ }^{13} \mathrm{C} \mathrm{NMR}\left(\mathrm{CDCl}_{3}, 75 \mathrm{MHz}\right): \delta 174.9,174.6,172.8$ and $164.8(\mathrm{C}=\mathrm{O})$, 142.0, 136.7, 135.0, 130.2, 128.9, 128.5, 128.0 and 127.6 (arom.), 70.1 (C-Me), $69.0\left(\mathrm{CH}_{3} \mathrm{O}\right), 61.8\left(\mathrm{OCH}_{2} \mathrm{CH}_{3}\right)$, 
$55.3\left(\mathrm{CH}_{2} \mathrm{~N}\right), 52.4,48.7$ and $24.7(\mathrm{CH}), 50.7\left(\mathrm{CH}_{3}-\mathrm{N}\right), 41.2\left(\mathrm{CH}_{2}-\mathrm{SO}_{2}\right), 19.5\left(\mathrm{CH}_{3} \mathrm{C}\right), 14.2\left(\mathrm{CH}_{3} \mathrm{CH}_{2} \mathrm{O}\right) . \mathrm{MS}(\mathrm{m} / \mathrm{z}): 542$ (35), 482 (100). Anal. Calcd. for $\mathrm{C}_{27} \mathrm{H}_{30} \mathrm{~N}_{2} \mathrm{O}_{8} \mathrm{~S}$ (542.60): C, 59.77; H, 5.57; N, 5.16. Found: C, 59.78; $\mathrm{H}, 5.24 ; \mathrm{N}$, 5.18 .

Methyl (1R,3S,3aR,6aS)-2-(2-((4-(ethoxycarbonyl)phenyl)sulfonyl)ethyl)-1,5-dimethyl-4,6-dioxo-3-phenyloctahydropyrrolo[3,4-c]pyrrole-1-carboxylate ( $\mathbf{(})-21 b$. Yield: $0.59 \mathrm{~g}(18 \%)$; white crystals from ethanol, $\mathrm{mp}$ 161-162 ${ }^{\circ} \mathrm{C}$. IR $v_{\mathrm{C}=0} 1700 \mathrm{~cm}^{-1} .{ }^{1} \mathrm{H}$ NMR $\left(\mathrm{CDCl}_{3}, 250 \mathrm{MHz}\right): \delta 8.09$ and 7.61 (AA'BB' syst., $2 \mathrm{H}+2 \mathrm{H}$, arom.), 7.38 and $6.92\left(\mathrm{~m}, 2 \mathrm{H}+3 \mathrm{H}\right.$, arom.), $4.45\left(\mathrm{q}, J 7 \mathrm{~Hz}, 2 \mathrm{H},-\mathrm{OCH}_{2} \mathrm{CH}_{3}\right), 4.09$ (d, J $\left.6 \mathrm{~Hz}, 1 \mathrm{H}, \mathrm{CH}-\mathrm{Ph}\right), 3.78\left(\mathrm{~s}, 3 \mathrm{H},-\mathrm{OCH}_{3}\right), 3.48$ (t, J $6 \mathrm{~Hz}, 1 \mathrm{H},-\mathrm{CH}-\mathrm{CHPh}), 3.20(\mathrm{~d}, J 6 \mathrm{~Hz}, 1 \mathrm{H}, \mathrm{CH}), 3.59$ and $2.45\left(\mathrm{~m}, 2 \mathrm{H}+2 \mathrm{H}, \mathrm{CH}_{2}-\mathrm{CH}_{2}\right), 2.80\left(\mathrm{~s}, 3 \mathrm{H}, \mathrm{CH}_{3}-\mathrm{N}\right), 1.45$ $\left(\mathrm{s}, 3 \mathrm{H}, \mathrm{CH}_{3}\right), 1.44\left(\mathrm{t}, 3 \mathrm{H}, \mathrm{J} 7 \mathrm{~Hz},-\mathrm{OCH}_{2} \mathrm{CH}_{3}\right) \cdot{ }^{13} \mathrm{C} \mathrm{NMR}\left(\mathrm{CDCl}_{3}, 75 \mathrm{MHz}\right): \delta$ 175.9, 174.6, 172.8 and $164.8(\mathrm{C}=\mathrm{O})$, 141.1, 138.1, 136.0, 130.1, 129.1, 128.6, 127.6 and 127.1 (arom.), 70.1 (C-Me), $69.3\left(\mathrm{CH}_{3} \mathrm{O}\right), 61.7\left(\mathrm{OCH}_{2} \mathrm{CH}_{3}\right)$, $55.1\left(\mathrm{CH}_{2} \mathrm{~N}\right), 52.3,48.3$ and $24.7(\mathrm{CH}), 54.3\left(\mathrm{CH}_{3}-\mathrm{N}\right), 43.4\left(\mathrm{CH}_{2}-\mathrm{SO}_{2}\right), 16.3\left(\mathrm{CH}_{3} \mathrm{C}\right), 14.2\left(\mathrm{CH}_{3} \mathrm{CH}_{2} \mathrm{O}\right) . \mathrm{MS}(\mathrm{m} / \mathrm{z}): 542$ (6), 483 (100). Anal. Calcd. for $\mathrm{C}_{27} \mathrm{H}_{30} \mathrm{~N}_{2} \mathrm{O}_{8} \mathrm{~S}$ (542.60): C, 59.77; H, 5.57; N, 5.16. Found: C, 59.75; H, 5.60; N, 5.15 .

Cleavage through oxidation and regeneration of the vinyl-sulfonyl benzoic ester 18. Compound 21a (0.22 g, $0.4 \mathrm{mmol})$ is dissolved in $\mathrm{CHCl}_{3}(20 \mathrm{~mL})$ and $\mathrm{mCPBA}(0.17 \mathrm{~g}, 1 \mathrm{mmol})$ was added portionwise to the cooled down solution $\left(0^{\circ} \mathrm{C}\right)$ under stirring. Temperature was then left to rise to ambient conditions and the reaction was continued for $2 \mathrm{ds}$. After this period of time, the solution was evaporated and the residue submitted to chromatographic purification, affording the nitrone 22 in $83 \%$ yield and the vinyl-sulfone 18 in $75 \%$ yield, found identical to the authentic sample previously prepared.

Methyl (1S,3aR,6aS)-1,5-dimethyl-2-( $\lambda^{1}$-oxidanyl)-4,6-dioxo-3-phenyl-1,3a,4,5,6,6a-hexahydro-2 $\lambda^{4}$-pyrrolo[3,4-c]pyrrole-1-carboxylate (22). Yield: $0.11 \mathrm{~g}$ (83\%); pale yellow crystals from chloroform, $\mathrm{mp} 186{ }^{\circ} \mathrm{C}$ (dec.). IR $v_{\mathrm{C}=0} 1701 \mathrm{~cm}^{-1} .{ }^{1} \mathrm{H}$ NMR $\left(\mathrm{CDCl}_{3}, 250 \mathrm{MHz}\right): \delta 8.64$ and $7.51(\mathrm{~m}, 2 \mathrm{H}+3 \mathrm{H}$, arom. $), 4.72(\mathrm{~d}, J 6 \mathrm{~Hz}, 1 \mathrm{H}, \mathrm{CH}-\mathrm{CPh})$, $3.73\left(\mathrm{~s}, 3 \mathrm{H},-\mathrm{OCH}_{3}\right), 3.53(\mathrm{~d}, J 6 \mathrm{~Hz}, 1 \mathrm{H},-\mathrm{CH}-\mathrm{CMe}), 3.01\left(\mathrm{~s}, 3 \mathrm{H}, \mathrm{CH}_{3}-\mathrm{N}\right), 2.00\left(\mathrm{~s}, 3 \mathrm{H}, \mathrm{CH}_{3}\right) .{ }^{13} \mathrm{C} \mathrm{NMR}_{(\mathrm{CDCl}}, 75$ $\mathrm{MHz}): \delta 176.9,174.8$ and $174.1(\mathrm{C}=\mathrm{O}), 136.8,133.2,131.2,130.3,128.9,128.6,127.6$ and 126.9 (arom. and quaternary C), $52.8\left(\mathrm{CH}_{3} \mathrm{O}\right), 47.1$ and $24.4(\mathrm{CH}), 46.3\left(\mathrm{CH}_{3}-\mathrm{N}\right), 22.1\left(\mathrm{CH}_{3} \mathrm{C}\right) . \mathrm{MS}(\mathrm{m} / \mathrm{z}): 316(59), 257(12), 241$ (34), 156 (73), 139 (100). Anal. Calcd. for $\mathrm{C}_{16} \mathrm{H}_{16} \mathrm{~N}_{2} \mathrm{O}_{5}$ (316.31): C, 60.76; H, 5.10; N, 8.80. Found: C, 60.75; H, $5.20 ; \mathrm{N}, 8.85$.

Preparation of the vinyl-sulfone supported on Wang's resin 25. Wang's resin ( $p$-benzyloxybenzyl alcohol resin, loading $0.7 \mathrm{mmol} / \mathrm{g}$ ) $\mathbf{W}-\mathbf{O H}$ was swollen in dry DCM (70 mL for $12 \mathrm{~g}$ of resin) for 5 minutes. A suspension of 2.2 equiv. of 4-vinylsulfonylbenzoic acid (24) in $70 \mathrm{~mL} \mathrm{DCM}$ and 1 equiv. of dicyclohexylcarbodiimide (DCC) (disopropylcarbodiimide, DIPCD, can be used alternatively) was added under gentle stirring. After 10 minutes, 10 mol\% 4-dimethylaminopyridine (DMAP) was added to the suspension and stirring was continued for $2 \mathrm{ds}$. After this period of time, the resin was filtered and washed carefully several times in sequence with DCM, $\mathrm{MeOH}$ and $\mathrm{Et}_{2} \mathrm{O}$ and finally dried under vacuum. Elemental analysis: for a $0.7 \mathrm{mmol} / \mathrm{g}$ loading resin, $\mathrm{S}$ requires 2.24\%; found 2.30\%. IR v $\mathrm{C}=01723 \mathrm{~cm}^{-1} .{ }^{13} \mathrm{C} \mathrm{NMR}\left(\mathrm{CDCl}_{3}, 75 \mathrm{MHz}\right): \delta 65.6\left(\mathrm{Ar}_{-} \mathrm{CH}_{2}-\mathrm{O}\right)$.

Preparation of resin 9. Resin 25 was swollen in DMF (50 mL for $3 \mathrm{~g}$ of resin) for 5 minutes and 2.5 equiv. of $(D, L)$-alanine methyl ester 19 were added under gentle stirring. After $2 \mathrm{ds}$ at $\mathrm{rt}$, the resin was filtered and washed carefully several times in sequence with $\mathrm{DCM}, \mathrm{MeOH}$ and $\mathrm{Et}_{2} \mathrm{O}$ and finally dried under vacuum. Elemental analysis: for a $0.7 \mathrm{mmol} / \mathrm{g}$ loading resin, requires $\mathrm{S}, 2.24 ; \mathrm{N}, 0.98 \%$; found $\mathrm{S}, 2.20 ; \mathrm{N}, 0.90 \%$.

IR $v_{\mathrm{NH}} 3324 ; v_{\mathrm{C}=0} 1734 \mathrm{~cm}^{-1} .{ }^{13} \mathrm{C} \mathrm{NMR}\left(\mathrm{CDCl}_{3}, 75 \mathrm{MHz}\right): \delta 175.2(\mathrm{C}=\mathrm{O}), 56.2\left(\mathrm{CH}_{2}-\mathrm{O}\right), 56.1\left(\mathrm{CH}_{3}\right), 51.8(\mathrm{CH}-\mathrm{N})$, $41.1\left(\mathrm{CH}_{2}-\mathrm{SO}_{2}\right), 18.8\left(\mathrm{CH}_{3}-\mathrm{CH}\right)$.

Cycloaddition reaction to prepare resin 10. Compound 9 was swollen in dry toluene ( $50 \mathrm{~mL}$ for $2 \mathrm{~g}$ of resin) for 5 minutes and 2 equiv. benzaldehyde and $\mathrm{N}$-methyl-maleimide were added under gentle stirring. The suspension was boiled for $4 \mathrm{ds}$. The resin was then filtered and washed carefully several times in sequence 
with $\mathrm{DCM}, \mathrm{MeOH}$ and $\mathrm{Et}_{2} \mathrm{O}$ and finally dried under vacuum. Elemental analysis: for a $0.7 \mathrm{mmol} / \mathrm{g}$ loading resin, requires S, 2.24; N, 1.96\%; found S, 2.00; N, 1.10\%. IR $v_{\mathrm{C}=0} 1760,1730$ and $1700 \mathrm{~cm}^{-1} .{ }^{13} \mathrm{C} \mathrm{NMR}\left(\mathrm{CDCl} \mathrm{N}_{3}, 75\right.$ $\mathrm{MHz}): \delta 175.1(\mathrm{C}=\mathrm{O}), 68.9\left(\mathrm{CH}_{3}-\mathrm{O}\right), 55.2\left(\mathrm{CH}_{2}-\mathrm{N}\right), 50.7\left(\mathrm{CH}_{3}-\mathrm{N}\right), 52.4,48.7$ and $24.7(\mathrm{CH}), 19.5\left(\mathrm{CH}_{3}-\mathrm{C}\right)$.

Cleavage of nitrone 22 from resin 10 through oxidation reaction. Resin 10 was swollen in chloroform (50 mL for $2 \mathrm{~g}$ of resin) and 2.2 equiv. of $m$ CPBA were added under gentle stirring at $0{ }^{\circ} \mathrm{C}$. After 2 das at rt, the resin 25 was then filtered and washed carefully several times in sequence with $\mathrm{DCM}, \mathrm{MeOH}$ and $\mathrm{Et}_{2} \mathrm{O}$ and finally dried under vacuum. The resin $\mathbf{2 5}$ obtained from the cleabage was found identical to the original one upon ${ }^{13} \mathrm{C} \mathrm{NMR}$ control spectrum. Elemental analysis: for a $0.7 \mathrm{mmol} / \mathrm{g}$ loading resin, requires $\mathrm{S}, 2.24 \%$; found $\mathrm{S}, 2.00 \%$; nitrogen absent. From the organic solution, nitrone $\mathbf{2 2}$ was isolated in $\mathbf{8 3 \%}$ yield, found identical to the sample previously obtained. The second diastereosomer is not reported here since it could be detected in very low amount $(<4 \%)$ just in the crude reaction mixture.

Cleavage by transesterification of resin 10. To a suspension of resin 10 in MeOH/THF 1:3 (50 mL for $2 \mathrm{~g}$ of resin), $\mathrm{NaCN}$ (1 equiv.) was added along with 7 equiv. $\mathrm{Et}_{3} \mathrm{~N}$. The micture was heated to $64{ }^{\circ} \mathrm{C}$ for $2 \mathrm{ds}$ under gentle stirring. The resin was then filtered and washed carefully several times in sequence with $\mathrm{DCM}, \mathrm{MeOH}$ and $\mathrm{Et}_{2} \mathrm{O}$ and finally dried under vacuum. The dried resin was found identical to the original Wang's resin $\left({ }^{13} \mathrm{C}\right.$ NMR control spectrum) and from the organic solution, upon evaporation of the solvents, a solid crystallized from ethanol, corresponding to compound 26, fully characterized. The minor diastereosomer was only detected in the crude reaction mixture.

Methyl (1R,3R,3aS,6aR)-2-(2-((4-(methoxycarbonyl)phenyl)sulfonyl)ethyl)-1,5-dimethyl-4,6-dioxo-3-phenyloctahydropyrrolo[3,4-c]pyrrole-1-carboxylate (26). Yield: $0.64 \mathrm{~g}(87 \%)$; colorless crystals from ethanol, $\mathrm{mp}$ 120-121 ${ }^{\circ} \mathrm{C}$. IR $v_{\mathrm{C}=0} 1691 \mathrm{~cm}^{-1} .{ }^{1} \mathrm{H}$ NMR $\left(\mathrm{CDCl}_{3}, 250 \mathrm{MHz}\right): \delta 8.05$ and 7.62 (AA'BB' syst., $2 \mathrm{H}+2 \mathrm{H}$, arom.), 7.28 and $6.85\left(\mathrm{~m}, 2 \mathrm{H}+3 \mathrm{H}\right.$, arom.), $4.34(\mathrm{~d}, J 6 \mathrm{~Hz}, 1 \mathrm{H}, \mathrm{CH}-\mathrm{Ph}), 4.00\left(\mathrm{~s}, 3 \mathrm{H},-\mathrm{OCH}_{3}\right), 3.75\left(\mathrm{~s}, 3 \mathrm{H}, \mathrm{CH}_{3} \mathrm{O}-\right), 3.44(\mathrm{t}, J 6 \mathrm{~Hz}$, $1 \mathrm{H},-\mathrm{CH}-\mathrm{CHPh}), 3.32(\mathrm{~d}, \mathrm{~J} 6 \mathrm{~Hz}, 1 \mathrm{H}, \mathrm{CH}), 3.29$ and $2.55\left(\mathrm{~m}, 2 \mathrm{H}+2 \mathrm{H}, \mathrm{CH}_{2}-\mathrm{CH}_{2}\right), 2.85\left(\mathrm{~s}, 3 \mathrm{H}, \mathrm{CH}_{3}-\mathrm{N}\right), 1.65(\mathrm{~s}, 3 \mathrm{H}$, $\left.\mathrm{CH}_{3}\right) .{ }^{13} \mathrm{C} \mathrm{NMR}\left(\mathrm{CDCl}_{3}, 75 \mathrm{MHz}\right): \delta 174.9,174.6,172.8$ and $165.3(\mathrm{C}=\mathrm{O}), 140.0,136.7,134.6,130.2,129.0,128.8$, 128.5 and 127.6 (arom.), $70.1(\mathrm{C}-\mathrm{Me}), 69.2\left(\mathrm{CH}_{3} \mathrm{O}\right), 69.0\left(\mathrm{OCH}_{3}\right), 55.2\left(\mathrm{CH}_{2} \mathrm{~N}\right), 52.4,48.7$ and $24.7(\mathrm{CH}), 50.7$ $\left(\mathrm{CH}_{3}-\mathrm{N}\right), 41.2\left(\mathrm{CH}_{2}-\mathrm{SO}_{2}\right), 19.5\left(\mathrm{CH}_{3} \mathrm{C}\right) . \mathrm{MS}(\mathrm{m} / \mathrm{z}): 528(5), 513(10), 497(62), 469$ (100). Anal. Calcd. for $\mathrm{C}_{26} \mathrm{H}_{28} \mathrm{~N}_{2} \mathrm{O}_{8} \mathrm{~S}$ (528.58): C, 59.08; $\mathrm{H}, 5.34 ; \mathrm{N}, 5.30$. Found: $\mathrm{C}, 59.10 ; \mathrm{H}, 5.38 ; \mathrm{N}, 5.28$.

Single crystal X-ray diffraction analysis of compound 21a. All crystallographic measurements were carried out at ambient temperature on a Stoe STADI4 diffractometer operating in the $\theta$ scan mode using graphite monochromated Copper-K $\alpha$ X-radiation ( $\lambda 1.54184 \AA$ ). . The data were corrected for Lorentz and polarization factors and for absorption (based on azimuthal psi-scans). The structure was solved by direct methods using SHELX S- $86^{23}$ and refined by full-matrix least-squares (based on $\mathrm{F}^{2}$ ) using SHELX S-93. ${ }^{24}$ All non-hydrogen atoms were refined with anisotropic displacement parameters. All hydrogen atoms were constrained to calculated positions ( $\mathrm{C}-\mathrm{H}$ 0.95, 0.98, 1.00 and 0.99 for phenyl, methyl, methane and methylene) and were assigned fixed anisotropic thermal parameters of $n\left(U_{e q}\right)$ of the parent non-hydrogen atom, where $n$ was 1.5 for methyl hydrogen atoms and 1.2 for all others. The weighting scheme $w=\left[\sigma^{2}\left(F_{0}\right)+(0.045 P)^{2}+1.1987 P\right]^{-1}$ was used. An ORTEP ${ }^{25}$ representation of the molecular structure of $21 \mathrm{a}$ is given (see text).

CCDC Deposition Number: 2108295.

\section{Acknowledgements}

Financial support by University of Leeds and Marie Curie Fellowship (Grant n. ERBFMBiCT961350) are gratefully acknowledged. Thank are also due to University of Pavia. 
A warm thank-you to Prof. R. Grigg for the opportunity given to join his research group at Leeds University. Thanks are due to Dr. V. Sridharan for the constant help in the experimental work, Dr. B. Watson for NMR spectra, Mrs. T. Marinko-Covell for MS spectra and Mr C. Huscroft for microanalyses. Dr. M. Thornton-Pett is gratefully acknowledged for X-ray analysis.

\section{Supplementary Material}

X-ray diffraction analysis of compound $\mathbf{2 1 a}$ is given in the supplementary material file associated with this paper.

\section{References}

1. Narayan, R.; Potowski, M.; Jia, Z.-J.; Antonchick, A. P.; Waldmann, H. Acc. Chem. Res. 2014, 47, 1296. https://doi.org/10.1021/ar400286b

2. Najera, C.; Sansano, J. M. Angew. Chem. Int. Ed. 2005, 44, 6272. https://doi.org/10.1002/anie.200501074

3. Boruah, M.; Konwar, D.; Sharma, S. D. Tetrahedron Lett. 2007, 48, 4535. https://doi.org/10.1016/i.tetlet.2007.04.131

4. Coldham, I.; Hufton, R. Chem. Rev. 2005, 105, 2765. https://doi.org/10.1021/cr040004c

5. Gallop, M. A.; Barrett, R. W.; Dover, W. J.; Fodor, S. P.; Gordon, E. M. J. Med. Chem. 1994, $37,1233$. https://doi.org/10.1021/jm00035a001

6. Hamper, B. C.; Dukesherer, D. R.; South, M. S. Tetrahedron Lett. 1996, 37, 3671. https://doi.org/10.1016/0040-4039(96)00659-4

7. Hollinshead, S. P. Tetrahedron Lett. 1996, 37, 9157. https://doi.org/10.1016/S0040-4039(96)02147-8

8. Barrett, A. G. M.; Boffey, R. J.; Frederiksen, M. U.; Newton, C. G.; Roberts, R. S. Tetrahedron Lett. 2001, 42, 5579.

https://doi.org/10.1016/S0040-4039(01)01061-9

9. Okada, H.; Akaki, T.; Oderaotoshi, Y.; Minakata, S.; Komatsu, M. Tetrahedron 2003, 59, 197. https://doi.org/10.1016/S0040-4020(02)01473-4

10. Komatsu, M.; Okada, H.; Akaki, T.; Oderaotoshi, Y.; Minakata, S. Org. Lett. 2002, 4, 3505. https://doi.org/10.1021/ol026634n

11. Bar-Nir, B. B.-A.; Portnoy, M. Heterocycles 2006, 67, 511. https://doi.org/10.3987/COM-05-S(T)47

12. Peng, G.; Sohn, A.; Gallop, M. A. J. Org. Chem. 1999, 64, 8342. https://doi.org/10.1021/jo990969+

13. Grigg, R.; Sridharan, V. Advances in Cycloaddition 1993, 3, 161.

14. Brown, A. R.; Rees, D. C.; Rankovic, Z.; Morphy, J. R. J. Am. Chem. Soc. 1997, 119, 3288. https://doi.org/10.1021/ja963829f

15. Horner, L.; Lindel, H. Phosphorous and Sulfur 1983, 15, 1. https://doi.org/10.1080/03086648308073274 
16. Werbel, L. M.; Newton, L.; Elslager, E. F. J. Heteroc. Chem. 1980, 17, 497. https://doi.org/10.1002/jhet.5570170315

17. Campaigne, E.; Meyer, W. W. J. Org. Chem. 1962, 27, 2835. https://doi.org/10.1021/jo01055a028

18. Grigg, R.; Sridharan, V. Advances in Cycloadditions Curran, D. J. Ed.; A. I: Press, 1993, Vol. 3, pp. $161-204$.

19. Grigg, R.; Montgomery, J.; Somasunderarm, A. Tetrahedron 1992, 48, 10431 and references therein. https://doi.org/10.1016/S0040-4020(01)88346-0

20. Faita, G.; Mella, M.; Mortoni, A.; Paio, A.; Quadrelli, P.; Seneci, P. Eur. J. Org. Chem. 2002, 1175. https://doi.org/10.1002/1099-0690(200204)2002:7<1175::AID-EJOC1175>3.0.CO;2-Z

21. Quadrelli, P.; Scrocchi, R.; Piccanello, A.; Caramella, P. J. Comb. Chem. 2005, 7, 887. https://doi.org/10.1021/cc050056v

22. Joshi, P. B.; Memeo, M. G.; Quadrelli, P. Tetrahedron Lett. 2017, 58, 3271. https://doi.org/10.1016/j.tetlet.2017.07.026

23. Sheldrick, G. M. Acta Crystallogr. Sect. A. 1990, 46, 467. https://doi.org/10.1107/S010876739000027

24. Sheldrick, G. M. SHELXL-93, A program for crystal structure refinement, University of Göttingen, Germany, 1993.

25. Jonhson, C. K. ORTEPII, Report ORNL-5138, Oak Ridge National Laboratory, Tennesee (USA), 1976. 